\title{
Synthesis, Characterization and Electrochemical Applications of Chiral Imprinted Mesoporous Ni Surfaces
}

\author{
Sunpet Assavapanumat, ${ }^{\dagger, *}$ Marisa Ketkaew, ${ }^{\dagger,+}$ Alexander Kuhn ${ }^{*}, *$ and Chularat Wattanakit ${ }^{*}$, \\ ${ }^{\dagger}$ School of Molecular Science and Engineering, School of Energy Science and Engineering and Nanocatalysts and \\ Nanomaterials for Sustainable Energy and Environment Research Network of NANOTEC, Vidyasirimedhi Institute of Sci- \\ ence and Technology, Rayong, 21210, Thailand. \\ ${ }^{*}$ University of Bordeaux, CNRS, UMR 5255, Bordeaux INP, Site ENSCBP, 16 avenue Pey Berland, 33607, Pessac, France.
}

\begin{abstract}
The enantioselective synthesis of chiral compounds is of crucial importance for a wide range of potential applications, especially in cosmetic and pharmaceutical industries. Recently, chiral imprinted mesoporous platinum films, produced by the electrodeposition of the metal, in the simultaneous presence of a lyotropic liquid crystalline phase of non-ionic surfactants as mesoporogens and chiral templates, have been applied as electrocatalysts and selective stationary phases for the asymmetric synthesis and separation of chiral compounds, respectively. However, platinum is an expensive metal and therefore it is mandatory to explore the possibility to apply this concept also to other metals. In this contribution, we propose mesoporous chiral imprinted nickel as an alternative cheap and earth-abundant metal. The designed surface layers not only demonstrate electrochemical discrimination between two enantiomers, but most importantly, also allow stereospecific electroreduction of a prochiral compound, with very significant enantioselectivity of up to $80 \%$ ee. These results open up very promising perspectives for the development of low cost non-noble metal matrices for the synthesis of chiral compounds.
\end{abstract}

\section{INTRODUCTION}

Engineering of chiral surfaces has been one of the most attractive topics in the chemical community because they can be used to generate enantiomerically pure compounds (EPC). ${ }^{1}$ Although, there are several methods that have been proposed to obtain a single enantiomer, ${ }^{2}$ asymmetric synthesis is one of the most promising approaches. ${ }^{3}$ Until now, asymmetric catalysis, based on the use of chiral catalysts, has been extensively illustrated with chiral coordination complexes, ${ }^{4}$ molecular imprinted polymers, ${ }^{5}$ and biocatalysts. ${ }^{6}$ Over the past decades, homogeneous catalysts have played an important role in asymmetric synthesis due to an efficient up-scaling of production. ${ }^{7}$ However, much effort is required to recover the catalyst from the reaction mixtures. ${ }^{8}$ Often, a highly efficient enantioselective synthesis is based on the use of biocatalysts, which provide a specific asymmetric environment for the generation of chiral molecules under mild conditions. ${ }^{6,9}$ Nevertheless, low efficiency, poor stability under operating conditions and a narrow substrate spectrum of biocatalysts are considered as key limitations. ${ }^{10}$

To mimic chiral biocatalytic platforms, many different approaches, for example based on molecular imprinting, ${ }^{11}$ molecular grafting, ${ }^{12}$ as well as organometallic ${ }^{13}$ and coordination chemistry ${ }^{4,14}$ have been explored. Among them, the molecular imprinting approach has been extensively developed, because it is easy to generate a large variety of chiral cavities. ${ }^{15}$ Over the past decade, the chiral molecular imprinting approach has been mostly focused on imprinted polymers (MIP), which can show high affinity and selectivity in chiral recognition. ${ }^{16}$ However, their highly flexible structure and the difficulty to retain the chiral information after template removal are main drawbacks. ${ }^{17}$ Therefore, other materials have also been explored in this context such as silica, ${ }^{18}$ silica/polymer hybrid materials ${ }^{19}$ or metals. ${ }^{20}$ In the latter case the recognition efficiency can be greatly enhanced when the chiral information is integrated in a mesoporous matrix. ${ }^{2 a, 2 e, 3 c, 3 d, 21}$ This has been illustrated with chiral-encoded mesoporous Pt obtained by electrodeposition of the metal in the simultaneous presence of a lyotropic crystalline phase and chiral compounds. The resulting materials have been successfully used for various applications ranging from enantioselective recognition, ${ }^{2 \mathrm{a}, 2 \mathrm{e}}$ asymmetric synthesis of chiral compounds, ${ }^{3 \mathrm{c}, 3 \mathrm{~d}}$ and chiral separation.$^{2 \mathrm{~h}}$

Although these structures have shown very interesting features from an academic point of view, a major drawback with respect to practical applications is the fact the platinum is an expensive precious metal with a deleterious environmental impact. $^{22}$ In order to open up realistic application perspectives, imprinting chiral information in earth-abundant firstrow transition metals, such as for example nickel, would be an extremely important achievement in terms of cost and sustainability. ${ }^{23}$ In addition, nickel is also an interesting alternative metal in terms of chemical features, because it shows high activity in several electrocatalytic reactions, such as hydrogen production or enantioselective hydrogenation, ${ }^{24}$ oxygen reduction $^{25}$ and especially electroreduction of organic molecules. ${ }^{26}$

It is well-known that the incorporation of mesoporous features into bulk materials leads to outstanding properties, especially a very high active surface area. ${ }^{27}$ To design such materials, there are many different approaches, including both chemical and electrochemical methods. ${ }^{28}$ Over the past decade, mesoporous $\mathrm{Ni}$ has been successfully obtained via electrodeposition in the presence of various types and concentrations of surfactants as mesoporogens. ${ }^{29}$ The resulting porous electrodes show a very high surface area, although they are only present as thin layers deposited with a low amount of charge. ${ }^{30}$ Many literature reports are dedicated to the (electro)catalytic applications of such high surface area nickel, but molecular imprinting of chiral information in such a matrix has not yet been demonstrated. 
In this contribution, we report the production of chiral mesoporous $\mathrm{Ni}$ surfaces by electrodeposition of $\mathrm{Ni}$ in the simultaneous presence of non-ionic surfactant (Brij C10) and a chiral compound (phenylethanol, PE). The chiral character of the generated surfaces is revealed by discriminatory electrooxidation of the two PE enantiomers. In addition, and most importantly, the designed material is used for the enantioselective electroreduction of acetophenone as a prochiral model compound to produce the initially imprinted PE enantiomer with a high excess.

\section{RESULTS AND DISCUSSION}

\section{Electrodeposition of chiral imprinted mesoporous Ni films}

Chiral encoded mesoporous $\mathrm{Ni}$ has been successfully prepared by electrodeposition from $\mathrm{Ni}$ acetate in the presence of a selfassembled lyotropic liquid crystalline phase and the desired enantiomer as shown in Scheme 1 (see Supporting Information for a detailed description). Scheme 1a represents the molecular structure of the chiral templates, (R)-PE and (S)-PE, which are the target molecules for the electroreduction of acetophenone. Due to the hydrophilic interaction (H-bonding) between the hydroxyl group of the chiral molecules and the head groups of the non-ionic surfactant, Brij C10, the chiral compounds are located preferentially at the outer surface of the surfactant columns constituting the self-assembled hexagonal structure $\left(\mathrm{H}_{1}\right)$ of the lyotropic liquid crystal phase (Scheme 1b). When metallic nickel is grown around this soft template (Scheme 1c), mesoporous channels and chiral imprinted cavities are obtained after removable of the template (Scheme 1d).

Microscopic characterisation of a Ni film, obtained by using a charge density of $4 \mathrm{C} \mathrm{cm}^{-2}$ for the electrodeposition, reveals a smooth surface with uniform thickness over the entire area (Figures $1 \mathrm{a}$ and $1 \mathrm{~b}$ ). Obviously, the thickness of the mesoporous $\mathrm{Ni}$ films can be easily tuned by changing the charge density used for the electrodeposition (Figure S1). For example, the thickness resulting from a deposition charge density of 1,2 and $4 \mathrm{C} \mathrm{cm}^{-2}$ is $1.0,1.8$ and $4.0 \mu \mathrm{m}$ respectively. TEM investigation of a film generated with a charge density of $100 \mathrm{mC} \mathrm{cm}^{-2}$, reveals a uniform mesopore size distribution in the range of $2.33 \pm 0.22 \mathrm{~nm}$ (Figure 1c), which is in agreement with the expected pore size for this type of surfactant.

In addition, to confirm the high active surface area of the film, the electrochemical properties in $1 \mathrm{M} \mathrm{KOH}$ were monitored by cyclic voltammetry $(\mathrm{CV})$. Well-defined oxidation and reduction peaks are observed in the potential range from 250 to $350 \mathrm{mV}$ and
100 to $250 \mathrm{mV}$ vs $\mathrm{Ag} / \mathrm{AgCl}$, respectively (Figure 1d). The current density of the oxide-layer formation correlates with the active surface area of the Ni electrodes. ${ }^{31}$ The relative roughness factors of the prepared electrodes obtained with various deposition charge densities of 1,2 and $4 \mathrm{C} \mathrm{cm}^{-2}$ are 28.3, 61 and 114.2, respectively, indicating a linear correlation (Figure S2). The relationship between the relative roughness factor and the thickness of the electrodes measured by SEM (Figure S1) leads as well to a linear dependence (Figure S2).

\section{Enantioselective recognition of chiral compounds at chiral imprinted mesoporous Ni surfaces}

In order to illustrate the enantioselective properties of the chiral encoded Ni layers, differential pulse voltammetry (DPV) was used for the enantioselective electrooxidation PE. Compared to cyclic voltammetry this allows decreasing the impact of capacitive current, which is very high for such mesoporous layers, and therefore a more pronounced discrimination in terms of faradaic current becomes possible. Prior to studying the enantioselective recognition properties, the complete removal of chiral template was confirmed by two independent methods: (i) examining the amount of removed chiral template as a function of rinsing time by UV-VIS spectroscopy; (ii) monitoring the electrooxidation current of eventually remaining chiral compound by DPV. As shown in Figure S3, a series of UV-Vis spectra of the different washing solutions was recorded to confirm the progressive template removal when rinsing for $36 \mathrm{~h}$. In addition, to further confirm the removal of chiral molecules, a DPV in supporting electrolyte $(50 \mathrm{mM} \mathrm{HCl})$ of chiral imprinted mesoporous $\mathrm{Ni}$ after rinsing for $36 \mathrm{~h}$ was measured in the potential range from 400 to $530 \mathrm{mV}$ vs. $\mathrm{Ag} / \mathrm{AgCl}$ as shown in Figure S4. Indeed, no oxidation peak of PE was observed from 410 to $530 \mathrm{mV}$ (oxidation region of PE) for the imprinted electrode after washing. To further confirm the absence of parasitic phenomena, the DPV signals for both enantiomers on a non-imprinted mesoporous nickel electrode were compared. As expected, identical DPV current densities for the electrooxidation of (S)-PE (red) and (R)-PE (blue) were observed, confirming the absence of chiral information (Figure 2a). In strong contrast, the chiral imprinted mesoporous $\mathrm{Ni}$ allows discriminating the two enantiomers (Figures $2 \mathrm{~b}$ and $2 \mathrm{c}$ ). Chiral mesoporous Ni imprinted with (S)-PE exhibits a more pronounced signal for (S)-PE (red) with respect to (R)-PE (blue), whereas the one imprinted with (R)-PE shows a significantly higher signal for (R)-PE (blue) compared to (S)-PE (red). These observations clearly confirm the presence of chiral information in these metal layers, even after removal of the chiral templates. However, due to the easy oxidation of nickel, it is difficult to maintain the chiral imprints when exposing the electrodes to positive potentials. ${ }^{32}$

Scheme 1. Illustration of the formation of a chiral imprinted mesoporous Ni film in the simultaneous presence of the lyotropic liquid crys-

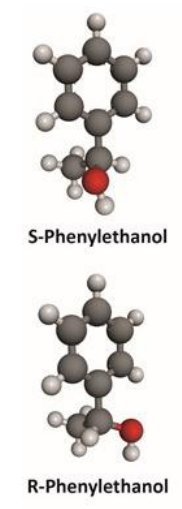

a)

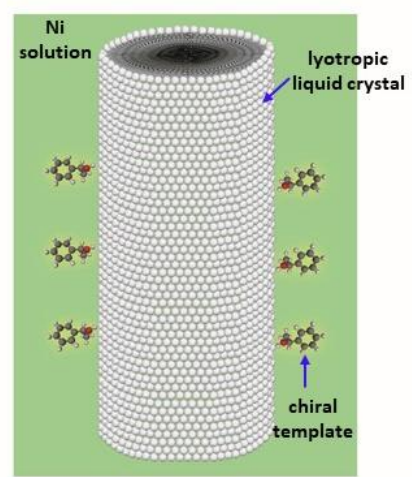

b)

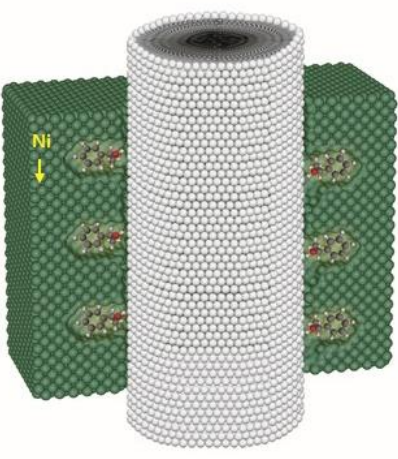

c)

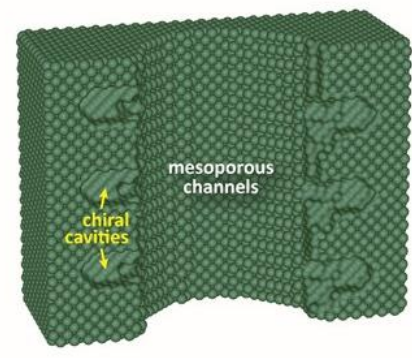

d)

talline phase $\left(\mathrm{H}_{1}\right)$ and chiral compounds: a) the molecular structure of (S) and (R)-PE; b) a self-assembled column of the lyotropic liquid 
crystalline phase in the presence of chiral molecules and Ni salt; c) Ni deposition in the presence of the two types of template; d) the chiral imprinted mesoporous Ni obtained after the dissolution of the templates
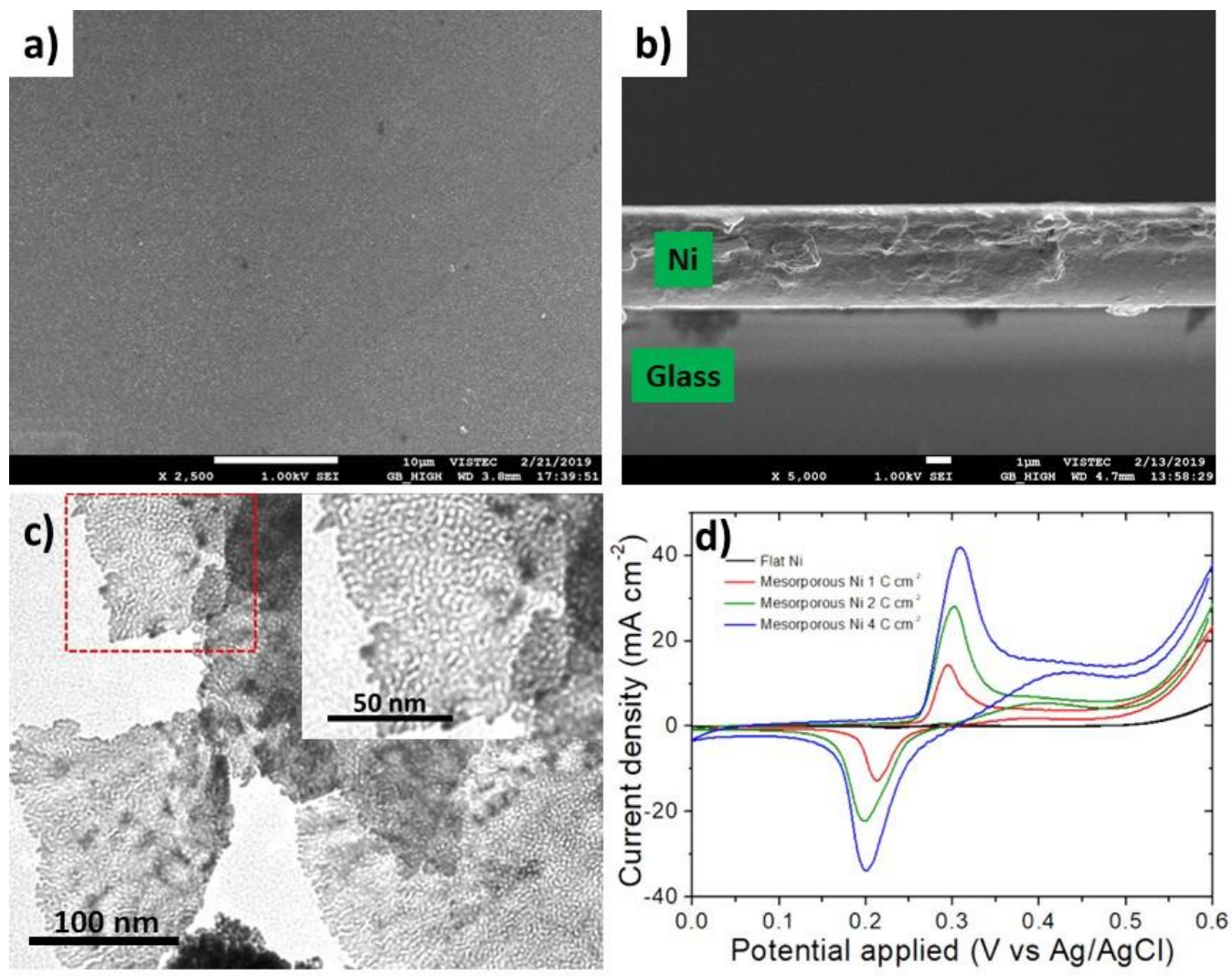

Figure 1. Characterization of chiral imprinted mesoporous Ni films: a) and b) SEM images (top view and cross section) of mesoporous nickel imprinted with S-PE obtained with a deposition charge density of $4 \mathrm{C} \mathrm{cm}^{-2}$ (scale bar $10 \mu \mathrm{m}$ (top view) and $1 \mu \mathrm{m}$ (cross section)); c) TEM image of a mesoporous Ni film obtained with a charge density of $100 \mathrm{mC} \mathrm{cm}$ and d) cyclic voltammograms of chiral-imprinted mesoporous $\mathrm{Ni}$ electrodes prepared with various charge densities compared to flat $\mathrm{Ni}$ in $1 \mathrm{M} \mathrm{KOH}$ at a scan rate of $100 \mathrm{mVs}^{-1}$.

\section{Asymmetric synthesis of chiral compounds at chiral imprinted mesoporous Ni surfaces}

In previous reports, the use of chiral encoded noble metal surfaces for the enantioselective electrosynthesis of chiral compounds from a prochiral precursor molecule has been described. ${ }^{3 c, 3 d}$ It was found that by fine-tuning the electrosynthesis potential, as well as applying potential pulses with varying duration, a highly selective production of chiral compounds is possible. ${ }^{3 \mathrm{~d}}$ In this contribution, we describe for the first time the possibility to use this concept also for non-noble metals. This is not an easy task as such metals
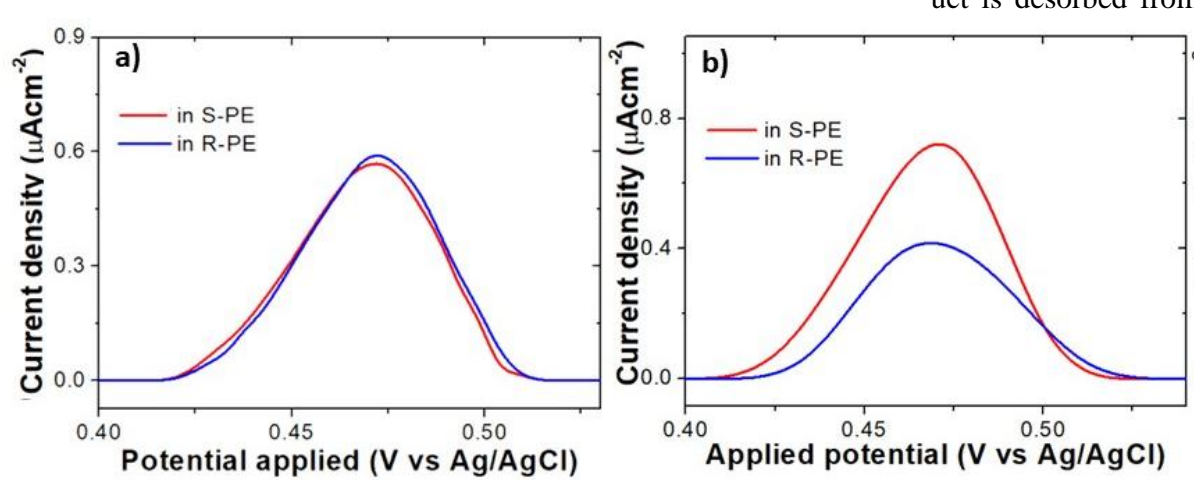

$2 d$. are much more reactive and might lose very quickly the chiral information by surface oxidation.

The electrochemical reduction of acetophenone to PE has been chosen as a model reaction. To achieve highly enantioselective synthesis, acetophenone needs first to adsorb in the chiral metal matrix (Scheme 2a). Subsequently, its carbonyl group $(C=O)$ is reduced in the chiral cavities (Scheme 2b). Due to the asymmetric local environment, a chiral product, which fits the spatial configuration of the encoded structure, is selectively produced during this hydrogenation step (Scheme $2 b$ and $2 c$ ). Finally, the chiral product is desorbed from the reaction site as represented in Scheme

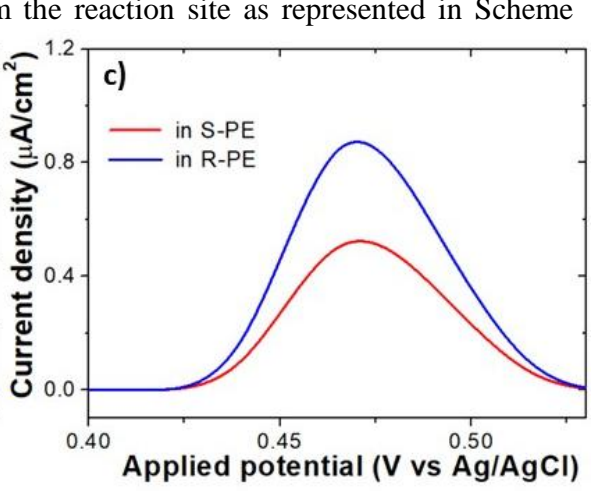


Figure 2. Differential pulse voltammograms (DPV) of the electrooxidation of (R)-PE (blue) and (S)-PE (red) in $50 \mathrm{mM} \mathrm{HCl}$ as a supporting electrolyte with different electrodes: a) flat Ni electrode, b) chiral mesoporous Ni electrode imprinted with (S)-PE, and (c) chiral mesoporous Ni electrode imprinted with (R)-PE.

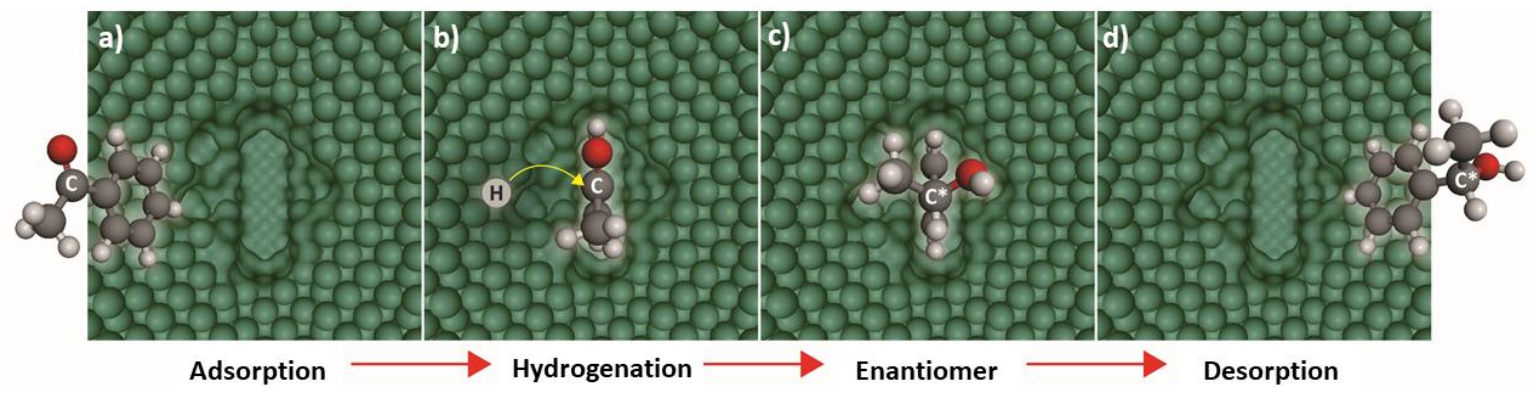

Scheme 2. Enantioselective synthesis steps of phenylethanol ((R)-PE or (S)-PE)) during the electroreduction of acetophenone: a) adsorption of the prochiral molecule, acetophenone, in the chiral cavity; (b) hydrogenation of acetophenone inside the chiral cavity; (c) formation of PE inside the corresponding chiral cavity; (d) desorption of the PE enantiomer.

An optimized potential of $-550 \mathrm{mV}$ vs. $\mathrm{Ag} / \mathrm{AgCl}$ was applied for the synthesis because the reduction of the prochiral functional $\mathrm{C}=\mathrm{O}$ group of acetophenone molecules starts around this potential. More negative potentials might induce an interference with proton reduction that may generate hydrogen bubbles, eventually destroying the mesoporous structure. Thus, the applied potential should be in the range from -450 to $-550 \mathrm{mV}$ vs. $\mathrm{Ag} / \mathrm{AgCl}$ in order to allow a selective electroreduction at the $\mathrm{C}=\mathrm{O}$ functional group (Figure S5).

As illustrated in Figure 3, the degree of enantioselectivity was determined by high-performance liquid chromatography (HPLC). Figure S6 shows the chromatograms of prochiral acetophenone, $(R)$-PE, and $(S)$-PE, with retention times of 10.1 (black), 13.5 (red), and 14.5 (blue) min, respectively. In a control experiment, using non-imprinted mesoporous $\mathrm{Ni}$ as a working electrode, a very low $\%$ enantiomeric excess (\% ee) of $1.9 \%$ is observed. Considering the error bar or the s.e.m. of the $\%$ ee value $( \pm 3.61$ $\%$ ), calculated by equation 2 in the supporting information, this indicates that there is no enantioselectivity in this case. However, when using chiral mesoporous Ni imprinted with (S)-PE, an \% ee of $23 \%$ was obtained after applying a constant potential for $12 \mathrm{~h}$. The corresponding control experiment, carried out with an R-(PE) imprinted electrode, resulted in an $\%$ ee of $-19 \%$. These first results are a promising proof-of-principle that chiral information can be retained by mesoporous nickel, even though the selectivity is rather moderate.

As previously reported, ${ }^{3 \mathrm{~d}}$ the concept of pulsed electrosynthesis with chiral encoded noble metal surfaces allows one to signifi- cantly improve the enantioselectivity due to a partial suppression of the competing reactions at the non-imprinted metal located at the external electrode surface. In order to improve the \% ee in the case of nickel surfaces, a potential of $-550 \mathrm{mV}$ vs. $\mathrm{Ag} / \mathrm{AgCl}$ was applied with different pulse durations. For a pulse duration of $30 \mathrm{~s}$ the $\%$ ee is significantly improved from $23 \%$ to $45 \%$ with respect to conventional steady-state electroreduction (Figure $3 \mathrm{~b}$ ). Even more pronounced enantioselectivity can be obtained when using a shorter pulse duration of $10 \mathrm{~s}$. In this case, the \% ee eventually reaches $80 \%$ as shown in Figure 3c. From a theoretical point of view, this can be understood by the fact that a decrease of pulse duration favors the reaction in the enantioselective mesopores due to the high internal surface area compared to the rather small outer non-imprinted surface. ${ }^{3 \mathrm{~d}}$ Short potential pulses, alternating with relaxation periods enable the produced enantiomer to evacuate the porous metal and allow diffusion of fresh prochiral precursor into the mesoporous matrix.

Compared to the previously studied platinum, nickel, as a nonnoble metal, has a much lower mechanical and chemical stability. ${ }^{33}$ Therefore, it is crucial to investigate also the stability of the imprinted chiral information. When chiral imprinted mesoporous $\mathrm{Ni}$ electrodes are immersed into the supporting solution without any applied potential under continuous stirring in nitrogen atmosphere, the mesoporous Ni layer gets nevertheless oxidized and is completely removed after 1 day, as illustrated in Figure S7. However, when a negative potential is applied, the mesoporous $\mathrm{Ni}$ layer is able to tolerate the synthesis conditions without significant degradation, due to the presence of a cathodic protection. ${ }^{34}$

Figure 3. Enantioselective electrosynthesis with chiral imprinted Ni electrodes: a) and b) HPLC chromatograms of electrosynthesis prod-
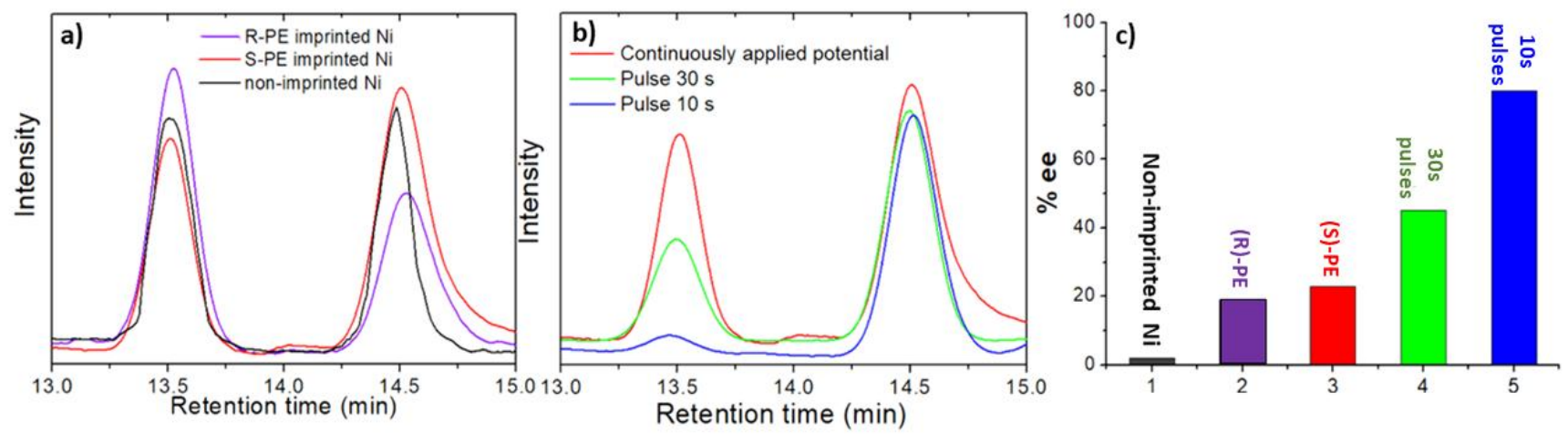

ucts obtained with imprinted electrodes in $10 \mathrm{mM}$ acetophenone and $1 \mathrm{M} \mathrm{NH}_{4} \mathrm{Cl}$ at a constant potential (a) or pulsed potential (b) mode for $\mathrm{E}=-0.55 \mathrm{~V}$ vs $\mathrm{Ag} / \mathrm{AgCl}$. The peak retention times of 13.5 and $14.5 \mathrm{~min}$ correspond to $(R)-\mathrm{PE}$ and $(S)$ - $\mathrm{PE}$, respectively. $\mathrm{c}) \mathrm{Histogram}$ summarizing the enantiomeric excess (\%ee) of the different experiments. Colour codes illustrate the different condition of electrosyn- 
thesis: non-imprinted Ni (black); (R)-PE imprinted Ni (purple) and (S)-PE imprinted Ni with continuously applied potential (red); (S)-PE imprinted Ni with 30s potential pulses (green) and (S)-PE imprinted Ni with 10s potential pulses (blue).

\section{CONCLUSIONS}

Chiral-encoded mesoporous nickel has been successfully prepared by electrodeposition from $\mathrm{Ni}$ acetate in the simultaneous presence of a lyotropic liquid crystal phase of non-ionic surfactant, Brij $\mathrm{C} 10$, and a chiral compound, phenylethanol. Characterization of the physical and electrochemical properties of the prepared films reveals that the active surface area is enhanced by two orders of magnitude compared to flat Ni. This allows a significant discrimination between (R)-PE and (S)-PE enantiomers, confirmed by DPV. Most importantly, the designed materials can be used for the enantioselective electroreduction of a prochiral compound, acetophenone, leading to preferential formation of one or the other phenylethanol enantiomer. The $\%$ ee can be greatly improved when using the concept of pulsed electrosynthesis. By fine-tuning the pulse duration, an optimized \%ee of up to $80 \%$ can be achieved, which is extremely high for such a non-noble heterogeneous catalytic system. Therefore this work is a crucial extension of the concept of chiral imprinting to non-noble metals and offers an interesting perspective for the development of designer materials for the chiral synthesis of high-added-value chemicals. Many pharmaceutical compounds actually contain chiral alcohol groups and it should be quite straight forward to extend the presented proof-of-principle experiments to such molecules. The chiral encoded layers could then replace or complement other approaches, for example based on the use of enzymes, with the chiral metal cavities playing the role of a biomimetic equivalent of the enzymatically active reaction site, allowing the stereoselective synthesis of chiral alcohols as important pharmaceutical products or intermediates. ${ }^{35}$

\section{ASSOCIATED CONTENT}

\section{Supporting Information.}

The Supporting Information is available free of charge on the ACS Publication website at DOI:.

\section{AUTHOR INFORMATION}

\section{Corresponding Author \\ *chularat.w@vistec.ac.th \\ *kuhn@enscbp.fr}

\section{ACKNOWLEDGMENT}

We would like to thank Sopon Butcha for TEM sample preparation and the grant from Vidyasirimedhi Institute of Science and Technology (VISTEC). This work was supported by the bilateral PICS program of CNRS. Chu. W. thanks the Thailand Research Fund (TRF) (MRG6180099), the Office of Higher Education Commission (OHEC) and TTSF research project supported by Thailand Toray Science Foundation. In addition, this work has been partially supported by the National Nanotechnology Canter (NANOTEC), NSTDA, Ministry of Science and Technology, Thailand, through its program of Research Network NANOTEC (RNN). S.A. is grateful to Campus France, the France Embassy in Thailand and VISTEC for a Ph.D. cotutelle scholarship. The project has also been partially funded by the European Research Council (ERC) under the European Union's Horizon 2020 research and innovation program (grant agreement $n^{\circ} 741251$, ERC Advanced grant ELECTRA).

\section{REFERENCES}

(1) (a) Mitchell, A. G. Racemic Drug: Racemic Mixture, Racemic Compound, or Pseudoracemate? J. Pharm. Pharmaceut. Sci. 1998, 1, 8-12. (b) McConathy, J.; Owens, M. J. Stereochemistry in Drug Action. Prim. Care Companion. J. Clin. Phychiatry. 2003, 5, 70-73. (c) Chhabra, N.; Aseri, M. L.; Padmanabhan, D. A Review of Drug Isomerism and Its Significance. Int. J. Appl. Basic. Med. Res, 2013, 3, 16-18. (d) Sannicolò, F.; Arnaboldi, S.; Benincori, T.; Bonometti, V.; Cirilli, R.; Dunsch, L.; Kutner, W.; Longhi, G.; Mussini, P. R. Panigati, M.; Pierini, M.; Rizzo, S. Potential-Driven Chirality Manifestations and Impressive Enantioselectivity by Inherently Chiral Electroactive Organic Films. Angew. Chem. Int. Ed. 2014, 53, 2623-2627. (e) Attard, G. A. Electrochemical Studies of Enantioselectivity at Chiral Metal Surfaces. J. Phy. Chem. B 2001, 105, 3158-3167.

(2) (a) Wattanakit, C.; Côme, Y. B. S.; Lapeyre, V.; Bopp, P. A.; Heim, M.; Yadnum, S.; Nokbin, S.; Warakulwit, C.; Limtrakul, J.; Kuhn, A. Enantioselective Recognition at Mesoporous Chiral Metal Surfaces. Nat. Comm. 2014, 5, 3325. (b) Pandey, I.; Kant, R. Electrochemical Impedance Based Chiral Analysis of Anti-Ascorbutic Drug: L-Ascorbic acid and DAscorbic acid using C-Dots Decorated Conductive Polymer Nano-Composite Electrode. Biosens. Bioelectron. 2016, 77, 715-724. (c) Sun, M.; Qu, A.; Hao, C.; Wu, X.; Xu, L.; Xu, C.; Kuang, H. Chiral Upconversion Heterodimers for Quantitative Analysis and Bioimaging of Antibiotic-Resistant Bacteria In Vivo. Adv. Mater. 2018, 30, 1804241. (d) Pu, C.; Xu, Y.; Liu, Q.; Zhu, A.; Shi, G. Enantiomers of Single Chirality Nanotube as Chiral Recognition Interface for Enhanced Electrochemical Chiral Analysis. Anal. Chem. 2019, 91, 3015-3020. (e) Yutthalekha, T.; Warakulwit, C.; Limtrakul, J.; Kuhn, A. Enantioselective Recognition of DOPA by Mesoporous Platinum Imprinted with Mandelic Acid. Electroanal. 2015, 27, 22092213. (f) Chen, C.; Shi, H.; Zhao, G. Chiral Recognition and Enantioselective Photoelectrochemical Oxidation toward Amino Acid on Single-Crystalline ZnO. J. Phy. Chem. C, 2014, 118, 12041-12049. (g) Bruno, R.; Marino, N.; Bartella, L.; Donna, L. D.; Munno, G. D.; Pardo, E.; Armentano, D. Highly Efficient Temperature-Dependent Chiral Separation with a Nucleotide-Based Coordination Polymer. Chem. Commun. 2018, 54, 6356-6359. (h) Assavapanumat, S.; Yutthalekha, T.; Garrigue, P.; Goudeau, B.; Lapeyre, V.; Perro, A.; Sojic, N.; Wattanakit, C.; Kuhn, A. Potential Induced FineTuning of the Enantioaffinity of Chiral Metal Phases. Angew. Chem. Int. Ed. 2019, 58, 3471-3475. (i) Anand, D.; Dhoke, G. V.; Gehrmann, J.; Garakani, T. M.; Davari, M. D.; Bocola, M.; Zhu, L.; Schwaneberg, U. Chiral Separation of D/L-Arginine with Whole Cells through An Engineered FhuA Nanochannel. Chem. Commun. 2019, 55, 5431-5434; (j) Ye, X.; Cui, J.; Li, B.; Li, N.; Wang, R.; Yan, Z.; Tan, J.; Zhang, J.; Wan, X. Enantiomer-Selective Magnetization of Conglomerates for Quantitative Chiral Separation. Nat. Commun. 2019, 10, 1964. (k) Kupai, J.; Rojik, E.; Huszthy, P.; Szekely, G. Role of Chiral and Macroring in Imprinted Polymers with Enantiodiscriminative Power. ACS Appl. Mater. Interfaces 2015, 7, 95169525. (1) Mallat, T.; Orglmeister, E.; Baiker, A. Asymmetric Catalysis at Chiral Metal Surfaces. Chem. Rev. 2007, 107, 4863-4890.

(3) (a) Pavlidis, I. V.; Weiß, M. S.; Genz, M; Spurr, P.; Hanlon, S. P.; Iding, H.; Bornscheuer, U. T. Identification of (S)Selective Transaminases for The Asymmetric Synthesis of Bulky Chiral Amines, Nat. Chem. 2016, 8, 1076-1082. (b) 
Simeonov, S. P.; Nunes, J. P. M.; Guerra, K.; Kurteva, V. B.; Afonso, C. A. M. Synthesis of Chiral Cyclopentenones. Chem. Rev. 2016, 116, 5744-5893. (c) Yutthalekha, T.; Wattanakit, C.; Lapeyre, V.; Nokbin, S.; Warakulwit, C.; Limtrakul, J.; Kuhn, A. Asymmetric Synthesis Using Chiral-Encoded Metal. Nat. Commun. 2016, 7, 12678. (d) Wattanakit, C.; Yutthalekha, T.; Assavapanumat, S.; Lapeyre, V.; Kuhn, A. Pulsed Electroconversion for Highly Selective Enantiomer Synthesis. Nat. Commun. 2017, 8, 2087. (e) Xue, Y. P.; Cao, C. H.; Zheng, Y. G. Enzymatic Asymmetric Synthesis of Chiral Amino Acids. Chem. Soc. Rev. 2018, 47, 1516-1561. (f) Wang, D. W.; Song, C.; Feng, W.; Cai, H.; Xu, D.; Deng, H.; Li, H.; Zheng, D.; Zhu, X.; Wang, H.; Zhu, S. Y.; Scully, M. O. Synthesis of Antiasymmetric Spin Exchange Interaction and Chiral Spin Clusters in Superconducting Circuits. Nat. Phys. 2019, $15,382-386$.

(4) (a) Kesanli, B.; Lin, W. Chiral Porous Coordination Networks: Rational Design and Applications in Enantioselective Processes. Coord. Chem. Rev. 2003, 246. 305-326. (b) Barker, J.; Kilner, M. The Coordination Chemistry of the Amidine Ligand. Coord. Chem. Rev.1994, 133, 219-300

(5) (a) Haupt, K.; Linares, A. V.; Bompart, M.; Bui, B. T. Molecular Imprinted Polymers. Top. Curr. Chem. 2012, 325, 1-28; (b) Lawton, T. J.; Pushkarev, V.; Wei, D.; Lucci, F. R.; Sholl, D. S.; Gellman, A. J.; Sykes, E. C. H. Long Range Chiral Imprinting of $\mathrm{Cu}$ (110) by Tartaric Acid. J. Phys. Chem. C 2013, 117, 22290-22297. (c) Alexander, C.; Davidson, L.; Hayes, W. Imprinted Polymers: Artificial Molecular Recognition Materials with Applications in Synthesis and Catalysis. Tetrahedron 2003, 59, 2025-2057.

(6) (a) Patel, R. N. Synthesis of Chiral Pharmaceutical Intermediates by Biocatalysis. Coord. Chem. Rev. 2008, 252, 659701. (b) Schmidt, S.; Büchsenschütz, H. C.; Scherkus, C.; Liese, A.; Gröger, H.; Bornscheuer, U. Biocatalytic Access to Chiral Polyesters by An Artificial Enzyme Cascade Synthesis. ChemCatChem. 2015, 7, 3951-3955. (c) Hepworth, L. J.; France, S. P.; Hussain, S.; Both, P.; Turner, N. J.; Flitsch, S. L. Enzyme Cascades in Whole Cells for the Synthesis of Chiral Cyclic Amines. ACS Catal. 2017, 7, 2920-2925.

(7) (a) Colacot, T. J. A Concise Update on the Applications of Chiral Ferrocenyl Phosphines in Homogeneous Catalysis Leading to Organic Synthesis. Chem. Rev. 2003, 103, 31013118. (b) Jones, M. D.; Raja, R.; Thomas, J. M.; Johnson, B. F. G.; Lewis, D. W.; Rouzaud, J.; Harris. K. D. M. Enhancing the Enantioselectivity of Novel Homogeneous Organometallic Hydrogenation Catalysts. Angew. Chem. Int. Ed. 2003, 42, 4326-4331. (c) Lühr, S.; Holz, J.; Börner, A. The Synthesis of Chiral Phosphorus Ligands for use in Homogeneous Metal Catalysis. ChemCatChem. 2011, 3, 1708-1730.

(8) (a) Müller, C.; Nijkamp, M. G.; Vogt, D. Continuous Homogeneous Catalysis. Eur. J. Inorg Chem. 2005, 2005, 40114021; (b) Xia, Q. H.; Ge, H. Q.; Ye, C. P.; Liu, Z. M.; Su, K. $\mathrm{X}$. Advances in Homogeneous and Heterogeneous Catalytic Asymmetric Epoxidation. Chem. Rev. 2005, 105, 1603-1662. (9) (a) Savile, C. K.; Janey, J. M.; Mundoff, E. C.; Moore, J. C.; Tam, S.; Jarvis, W. R.; Colbeck, J. C.; Krebber, A.; Fleitz, F. J.; Brands, J.; Davine, P. N.; Huisman, G. W.; Hughes, G. J. Biocatalytic Asymmetric Synthesis of Chiral Amines from Ketones Applied to Sitagliptin Manufacture. Science 2010, 329, 305-309. (b) Green, A. P.; Turner, N. J.; O'Reilly, E. Chiral Amine Synthesis Using $\square$-Transaminases: An Amine Donor that Displaces Equilibria and Enables High-Throughput Screening. Angew. Chem. Int. Ed. 2014, 53, 10714-10717. (c) Aleku, G. A.; France, S. P.; Man, H.; Sanchez, J. M.; Montgomery, S. L.; Sharma, M.; Leipold, F.; Hussain, S.; Grogan, G.; Tuner, N. J. A Reductive Aminase from Aspergillus Oryzae. Nat. Chem. 2017, 9, 961-969.
(10) (a) Reetz, M. T. What are the Limitations of Enzymes in Synthetic Organic Chemistry? Chem. Rec. 2016, 16, 24492459. (b) Truppo, M. D. Biocatalysis in the Pharmaceutical Industry: The Need for Speed. ACS Med. Chem. Lett. 2017, 8, 476-480.

(11) (a) Vlatakis, G.; Andersson, L. I.; Müller, R.; Mosbach, K. Drug Assay Using Antibody Mimics Made by Molecular Imprinting. Nature 1993, 361, 645-647; (b) Alexander, C.; Andersson, H. S.; Andersson, L. I.; Ansell, R. J.; Kirsch, N.; Nicholls, L. A.; Mahony, J. O.; Whitecombe, M. J. Molecular Imprinting Science and Technology: a Survey of the Literature for the Years up to and Including 2003. J. Mol. Recognit. 2003, 19, 106-180. (c) Vasapollo, G.; Sole, R. D.; Mergola, L.; Lazzoi, M. R.; Scardino, A.; Scorrano, S.; Mele, G. Molecularly Imprinted Polymers: Present and Future Prospective. Int. J. Mol. Sci. 2011, 12, 5908-5945. (d) Verheyen, E.; Schillemans, J. P.; van Wijk, M.; Demeniex, M. A.; Hennink, W. E.; van Nostrum, C. F. Challenges for the Effective Molecular Imprinting of Proteins. Biomaterials. 2011, 32, 3008-3020; (e) Chen, L.; Wang, X.; Lu, W.; Wu, X.; Li, J. Molecular Imprinting: Perspectives and Applications. Chem. Soc. Rev. 2016, 45, 2137-2211.

(12) (a) Mondal, P. C.; Fontanesi, C.; Waldeck, D. H.; Naaman, R. Field and Chirality Effects on Electrochemical Charge Transfer Rates: Spin Dependent Electrochemistry. ACS Nano 2015, 9, 3377-3384; (b) Xiang, S.; Zhang, Y.; Xin, Q.; Li, C. Asymmetric Epoxidation of Allyl Alcohol on OrganicInorganic Hybrid Chiral Catalysts Grafted onto the Surface of Silica and in the Mesopores of MCM-41. Angew. Chem. Int. Ed. 2002, 41, 821-824.

(13) (a) Lee, S. J.; Hu, A.; Lin, W. The First Chiral Organometallic Triangle for Asymmetric Catalysis. J. Am. Chem. Soc. 2002, 124, 12948-12949. (b) Sinou, D. Asymmetric Organometallic-Catalyzed Reactions in Aqueous Media. Adv. Synth. Catal. 2002, 344, 211-237.

(14) (a) Meeuwissen, J.; Reek, J. N. H. Supramolecular Catalysis beyond Enzyme Mimics. Nat. Chem. 2010, 2, 615-621. (b) Deuss, P. J.; Heeten, R. D.; Lann, W. Kamer, P. C. J. Bioinspired Catalyst Design and Artificial Metalloenzymes. Chem. Eur. J. 2011, 17, 4680-4698; (c) Luo, M.; Zhang, J. C.; Yin, H.; Wang, C. M.; Morris-Natschke, S.; Lee, K. H. OneStep Templated Synthesis of Chiral Organometallic Salicyloxazoline Complexes. BCM Chemistry 2019, 13, 1-9.

(15) (a) Mosbach, K.; Ramström, O. The Emerging Technique of Molecular Imprinting and Its Future Impact on Biotechnology. Nature Biotechnol 1996, 14, 163-170; (b) Kulsing, C.; Knob, R.; Macka, M.; Junor, P.; Boysen, R. I.; Hearn, M. T. W. Molecular Imprinted Polymeric Porous Layers in Open Tubular Capillaries for Chiral Separations. J. Chromatogr. A. 2014, 1354, 85-91.

(16) (a) Masqué, N.; Marcé, R.; Borrull, M. F.; Cormack, P. A. G;. Sherrington, D. C. Synthesis and Evaluation of a Molecularly Imprinted Polymer for Selective On-Line Solid-Phase Extraction of 4-Nitrophenol from Environmental Water. Anal. Chem. 2000, 72, 4122-4126. (b) Wang, J.; Cormack, P. A. G.; Sherrington, D. C.; Khoshdel, E. Monodisperse, Molecularly Imprinted Polymer Microspheres Prepared by Precipitation Polymerization for Affinity Separation Applications. Angew. Chem. Int. Ed. 2003, 42, 5336-5338; (c) Saylan, Y.; Yilmaz, F.; Özgür, E.; Derazshamshir, A.; Yavuz, H.; Denizil, A. Molecular imprinting of Macromolecules for Sensor Applications. Sensors, 2017, 17, 898.

(17) Chen, L.; Xu, S.; Li, J.; Recent Advances in Molecular Imprinting Technology: Current Status, Challenges and Highlighted Applications. Chem. Soc. Rev. 2011, 40, 2922-2942.

(18) Li, Z.; Xu, H.; Wu, D.; Zhang, J.; Liu, X.; Gao, S.; Kong, Y. Electrochemical Chiral Recognition of Tryptophan Isomers 
Based on Nonionic Surfactant-Assisted Molecular Imprinting Sol-Gel Silica. ACS Appl. Mater. 2019, 11, 2840-2848.

(19) Liu, X. L.; Tsunega, S.; Ito, T.; Takanashi, M.; Saito, M.; Kaikake, K.; Jin, R. H. Double Chiral Hybrid Materials: Formation of Chiral Phenolic Resin on Polyamine-Associated Chiral Silica. Chem. Lett. 2017, 46, 1518-1521.

(20) (a) Hao, C.; Xu, L.; Ma, W.; Wu, X.; Wang, L.; Kuang, $\mathrm{H}$,; Xu, C. Unusual Circularly Polarized Photocatalytic Activity in Nanogapped Gold-Silver Chiroplasmonic Nanostructures. Adv. Funct. Mater. 2015, 25, 5816-5822. (b) Riva, S. Chirality in Metals: An Asymmetrical Journey Among Advanced Functional Materials. J. Mater. Sci. Technol. 2016, 33, 795-808. (c) Wattanakit, C. Chiral Metals as Electrodes. Curr. Opin.Electrochem. 2017, 7, 54-60. (d) Switzer, J. A.; Kothari, H. M.; Poizot, P.; Nakanishi, S.; Bohannan, E. W. Enantiospecific Electrodeposition of a Chiral Catalyst. Nature 2003, 425, 490-493. (e) Avnir, D. Recent Progress in the Study of Molecularly Doped Metals. Adv. Mater. 2018, 30, 1706804. (f) Pachón, L. D.; Yosef, I.; Markus, T. Z.; Naaman, R.; Avnir, D.; Rothenberg, G. Chiral Imprinting of Palladium with Cinchona Alkaloids, Nat. Chem. 2009, 1, 160-164. (g) Kelso, M. V.; Tubbesing, J. Z.; Chen, Q.; Switzer, J. A. Epitaxial Electrodeposition of Chiral Metal Surfaces on Silicon (643). J. Am. Chem. Soc. 2018, 140, 15812-15819.

(21) Fang, Y.; Li, C.; Bo, J.; Henzie, J.; Yamauchi, Y.; Asahi, T. Chiral Sensing with Mesoporous Pd@Pt Nanoparticles. Chemelectrochem 2017, 4, 1832-1835.

(22) (a) Brubaker, P. E.; Moran, J. P.; Bridbord, K.; Hueter, F. G. Noble Metals: Toxicological Appraisal of Potential New Environmental Contaminants. Environ Health Perspect. 1975, 10, 39-56. (b) Balcerzak, M. Encyclopedia of Analytical Chemistry: Applications, Theory and Instumentation 2015. (c) Vent, G.; Milne, R. A. Cost Accounting Practices at Precious Metal Mines: A Comparative Study, 1869-1905. Accounting History 1997, 2, 77-105. (d) Saurat, M.; Bringezu, S. Platinum Group Metal Flows of Europe, Part 1. J. Ind. Ecol. 2008, 12, 754-767.

(23) (a) Bullock, R. M.; Abundant Metals Give Precious Hydrogenation Performance. Science, 2013, 342, 1054-1055. (b) Yang, B.; Burch, R.; Hardacre, C.; Headdock, G.; Hu, P. Origin of the Increase of Activity and Selectivity of Nickel Doped by $\mathrm{Au}, \mathrm{Ag}$, and $\mathrm{Cu}$ for Acetylene Hydrogenation. ACS Catal. 2012, 2, 1027-1032.

(24) (a) Kilgore, U. J.; Robert, J. A. S.; Pool, D. H.; Appel, A. M.; Stewart, M. P.; DuBois, M. R.; Dougherty, W. G.; Kassel, W. S.; Bullock, R. M.; Dubois, D. L. $\left[\mathrm{Ni}\left(\mathrm{P}^{\mathrm{Ph}}{ }_{2} \mathrm{~N}^{\mathrm{C} 6 \mathrm{H} 4 \mathrm{x}}{ }_{2}\right)_{2}\right]^{2+}$ Complexes as Electrocatalysts for $\mathrm{H}_{2}$ Production: Effect of Substituents, Acids and Water on Catalytic Rates. J. Am. Chem. Soc. 2011, 133, 5861-5872. (b) Bennett, A.; Christie, S.; Keane, M. A.; Peacock, R. D.; Webb, G. The Enantioselective Hydrogenation of Methylacetoacetate over Nickel Catalysts Modified with Tartaric Acid. Catal. Today 1991, 10, 363370. (c) Vedenyapin, A. A.; Chankvetadze, B. G.; Klabunavakii, E. I. Studies of Copper-Nickel Catalysts for Enantioselective Hydrogenation. React. Kinet. Catal. 1934, 24, 77-80. (d) Li, Y. Y.; Yu, S. L.; Shen, W. Y.; Gao, J. X. Iron-, Cobalt-, and Nickel-Catalyzed Asymmetric Transfer Hydrogenation and Asymmetric Hydrogenation of Ketones. Acc. Chem. Res. 2015, 48, 2587-2598.

(25) Roche, I.; Chaînet, E.; Chatenet, M.; Vondrák, J. CarbonSupported Manganese Oxide Nanoparticles as Electrocatalysts for the Oxygen Reduction Reaction (ORR) in Alkaline Medium: Physical Characterizations and ORR Mechanism. J. Phys. Chem. C 2007, 111, 1434-1443.

(26) (a) Guan, Y. Q.; Han, Z.; Li, X.; You, C.; Tan, X.; Lv,H.; Zhang, X. A Cheap Metal for a Challenging Task: NickelCatalyzed Highly Diastero- and Enantioselective Hydrogena- tion of Tetrasubstituted Fluorinated Enamides. Chem. Sci. 2019, 10, 252-256. (b) Shen, X.; Li, Y.; Wen, Z.; Cao, S.; Hou, X.; Gong, L. A Chiral Nickel DBFOX Complex as a Bifunctional Catalyst for Visible-Light-Promoted Asymmetric Photoredox Reactions. Chem. Sci. 2018, 9, 4562-4568.

(27) (a) Attard, G. S.; Bartlett, P. N.; Coleman, N. R. B.; Elliott, J. M.; Owen, J. R.; Wang, J. H. Mesoporous Platinum Films from Lyotropic Liquid Crystalline Phases. Science, 1997, 278, 838-840. (b) Attard, G. S.; Glyde, J. C.; Göltner, C. G. Liquid-Crystalline Phases as Templates for the Synthesis of Mesoporous Silica. Nature, 1995, 378, 366-368.

(28) (a) Lee, J.; Kim, J.; Hyeon, T. Recent Progress in the Synthesis of Porous Carbon Materials. Adv. Mater. 2006, 18, 2073-2094 (b) Ramirez, J. P.; Christensen, C. H.; Egeblad, K.; Christensen, C. H.; Groen, J. C. Hierarchical Zeolites: Enhanced Utilisation of Microporous Crystals in Catalysis by Advances in Materials Design. Chem. Soc. Rev. 2008, 37, 2530-3542; (c) Reculusa, S.; Heim, M.; Gao, F.; Mano, N.; Ravaine, S.; Kuhn, A. Design of Catalytically Active Cylindrical and Macroporous Gold Microelectrodes. Adv. Funct. Mater. 2011, 21, 691-698. (d) Xiao, C.; Li, Y.; Lu, X..; Zhao, C. Bifunctional Porous $\mathrm{NiFe} / \mathrm{NiCo}_{2} \mathrm{O}_{4} / \mathrm{Ni}$ Foam Electrodes with Triple Hierarchy and Double Synergies for Efficient Whole Cell Water Splitting. Adv. Func. Mater. 2016, 26, 3515-3523. (e) Rouya, E.; Cattarin, S.; Reed, M. L. Kelly, R. G.; Zangari, G. Electrochemical Characterization of the Surface Area of Nanoporous Gold Films. J. Electrochem. Soc. 2012, 159, K97K102.

(29) (a) Yusake, Y.; Tokihiko, Y.; Hitomi, M.; Masato, T.; Tetsuro, S.; Toshiyuki, M.; Tetsuya, O.; Kazuyuki, K. Highly Ordered Mesoporous Ni Particles by Electroless Deposition from Lyotropic Liquid Crystals. Chem. Lett. 2004, 33, 542543. (b) Campbell, R.; Bakker, M. G. Electrodeposition of Mesoporous Nickel onto Foamed Metals Using Surfactant and Polymer Templates. J. Porous Mater. 2004, 11, 63-69. (c) Assavapanumat, S.; Ketkaew, M. Garrigue, P.; Lapeyre, V.; Reculusa, S.; Wattanakit, C.; Kuhn, A. Hierarchical Multiporous Nickel for Oxygen Evolution Reaction in Alkaline Media. Chem CatChem. 2019, DOI: 10.1002/cctc.201901509 .

(30) Nelson, P. A.; Elliott, J. M.; Attard, G. S.; Owen, J. R. Mesoporous Nickel/Nickel Oxide-a Nanoarchitectured Electrode. Chem. Mater. 2002, 14, 524-529.

(31) (a) Singh, A.; Chang, S. L. Y.; Hocking, R. K.; Bach, U.; Spiccia, L. Highly Active Nickel Oxide Water Oxidation Catalysts Deposited from Molecular Complexes. Energy Environ. Sci. 2013, 6, 579-586. (b) Zhang, X.; Shi, W.; Zhu, J.; Zhao,W.; Ma, J.; Mhaisalkar, S.; Maria, T. L.; Yang, Y.; Zhang, H.; Hng, H. H.; Yan, Q. Synthesis of Porous NiO Nanocrystals with Controllable Surface Area and their Application as Supercapacitor Electrodes. Nano. Res. 2010, 3, 643652.

(32) (a) May, J. W.; Carroll, C. E. Ionic Monolayers on Metals: II. Neutral Mixed Layers and Surface Reconstruction. Surface Science 1972, 29, 85-113. (b) Ostyn, K. M.; Carter, C. B. On the Reduction of Nickel Oxide. Surface Science 1982, 121, 360-374; (c) Alfè, D.; Gironcoli, S.; Baroni, S. The Reconstruction of Nickel and Rhodium (001) Surfaces upon Carbon, Nitrogen or Oxygen Adsorptions. Surface Science 1999, 437, 18-28.

(33) (a) Benjamin, J. S. Dispersion Strengthened Superalloys by Mechanical Alloying. Metallurgical Transactions 1970, 1 , 2943-2951. (b) Scorzelli, R. B. A Study of Phase Stability in Invar $\mathrm{Fe}-\mathrm{Ni}$ Alloys Obtained by Non-Conventional methods. Hyperfine Interactions, 1997, 110, 143-150. (c) Inoue, A. Stabilization of Metallic Supercooled Liquid and Bulk Amorphous Alloys. Acta Materialia, 2000, 48, 279-306. 
(34) (a) Pedeferri, P. Cathodic Protection and Cathodic Prevention. Construction and Building Materials 1996, 10, 391402. (b) Bates, J. F. Cathodic Protection to Prevent Crevice Corrosion of Stainless Steels in Halide Media. Corrosion 1973, 29, 28-32; (c) Mears, R. B.; Brown, R. H. A Theory of Cathodic Protection. J. Electrochem. Soc. 1938, 74, 519-531.

(35) (a) Chen, B. S.; De Souza, F. Z. R. Enzymatic Synthesis of Enantiopure Alcohols: Current state and Perspectives. RSC
$A d v$, 2019, 9, 1202-2115. (b) Zheng, Y. G.; Yin, H. H.; Yu, D. F.; Chen, X.; Tang, X. T.; Zhang, X. J.; Xue, Y. P.; Wang, Y. J.; Liu, Z. Q. Recent Advances in Biotechnological Applications of Alcohol Dehydration. Appl. Microbiol. Biotechnol. 2017, 101, 987-1001. 
